\title{
Insidensi dan Faktor Risiko Hipotensi pada Pasien yang Menjalani Seksio Sesarea dengan Anestesi Spinal di Rumah Sakit Dr. Hasan Sadikin Bandung
}

\author{
Rini Rustini, ${ }^{1}$ Iwan Fuadi, ${ }^{2}$ Eri Surahman ${ }^{2}$ \\ ${ }^{1}$ Bagian Anestesiologi dan Terapi Intensif Fakultas Kedokteran Universitas Andalas \\ Rumah Sakit Umum Pusat M. Djamil Padang, ${ }^{2}$ Departemen Anestesiologi dan Terapi Intensif \\ Fakultas Kedokteran Universitas Padjadjaran/Rumah Sakit Dr. Hasan Sadikin Bandung
}

\begin{abstract}
Abstrak
Hipotensi merupakan komplikasi yang sering terjadi setelah tindakan anestesi spinal pada pasien seksio sesarea. Hipotensi terjadi akibat blokade simpatis terhadap aktivitas vasomotor pembuluh darah serta penekanan aorta dan vena kava inferior oleh uterus yang membesar terutama pada saat pasien telentang. Tujuan penelitian ini adalah mengetahui insidensi hipotensi dan faktor risiko yang berhubungan dengan kejadian hipotensi pada pasien yang menjalani seksio sesarea dengan anestesi spinal di Rumah Sakit Dr. Hasan Sadikin Bandung. Penelitian observasional potong lintang (cross sectional) ini dilakukan pada 90 subjek pasien yang menjalani seksio sesarea dengan anestesi spinal pada periode bulan April-Mei 2015. Pengolahan data dengan analisis univariabel untuk melihat gambaran proporsi variabel masing-masing yang disajikan secara deskriptif. Hasil penelitian menunjukkan insidensi hipotensi 49\%. Faktor risiko yang menyebabkan hipotensi maternal menunjukkan hasil yang tidak signifikan berhubungan dengan kejadian hipotensi $(p>0,05)$. Perbedaan insidensi hipotensi maternal setelah tindakan anestesi spinal dan faktor risiko yang memengaruhinya dengan penelitian sebelumnya karena perbedaan jumlah sampel penelitian, perbedaan definisi hasil yang digunakan, perbedaan tempat penelitian, dan perbedaan metode pengumpulan data.
\end{abstract}

Kata kunci: Anestesi spinal, faktor risiko, hipotensi, insidensi, seksio sesarea

\section{Incidence and Risk Factors of Hypotension in Patients Undergoing Cesarean Section with Spinal Anesthesia in Dr. Hasan Sadikin General Hospital Bandung}

\begin{abstract}
The most common serious complication associated with spinal anesthesia for C-section is hypotension. These hemodynamic changes result from a blockade of sympathetic vasomotor activity that is accentuated by the compression of the aorta and inferior vena cava by the gravid uterus when the patient is in the supine position. The purpose of this study was to describe the incidence of hypotension in patients undergoing cesarean section with spinal anesthesia in Dr. Hasan Sadikin General Hospital Bandung and to obtain a description of risk factors associated with the incidence of hypotension. A cross-sectional observational study was conducted on 90 subjects consisting of patients undergoing cesarean section with spinal anesthesia during the period of April-May 2015. The data processing performed was the univariable analysis to see the picture of the proportion of each variable, which were presented descriptively. The results showed $49 \%$ incidence of hypotension. There was an insignificant association between the risk factors of maternal hypotension after spinal anesthesia for cesarean section insignificant association with the incidence of hypotension ( $p>0.05$ ). Differences in the incidence of maternal hypotension after spinal anesthesia and risk factors as stated in this study when compared to previous studies are due to differences sample size, definitions, place, and data collection methods.
\end{abstract}

Key words: Cesarean section, hypotension, incidence, risk factors, spinal anesthesia

Korespondensi: Rini Rustini, dr., SpAn, SMF Anestesiologi dan Terapi Intensif Fakultas Kedokteran Universitas Andalas Rumah Sakit Umum Pusat M. Djamil Padang, Jl. Perintis Kemerdekaan Padang, Tlpn 0751-30733, Mobile 08122424458,Email rini.ummukhalid@gmail.com 


\section{Pendahuluan}

Hipotensi merupakan salah satu efek samping anestesia spinal yang dilakukan pada wanita hamil dengan angka kejadian sekitar $80 \%{ }^{1,2}$ Efek kardiovaskular akibat tindakan anestesia spinal berhubungan erat dengan level blokade simpatis yang mencapai persarafan setinggi torakal 1 sampai lumbal 2 (T1-L2). Blokade simpati akibat anestesia spinal menyebabkan dilatasi pembuluh darah sehingga menurunkan resistensi pembuluh darah sistemik yang akan menyebabkan hipotensi. ${ }^{3,4}$

Angka kejadian dan juga derajat hipotensi setelah anestesia spinal pada wanita hamil yang menjalani seksio sesarea dipengaruhi oleh beberapa faktor risiko, yaitu usia, tinggi dan berat badan, body mass index (BMI), posisi uterus miring ke kiri, cairan prehidrasi, dosis bupivakain, dosis adjuvan anestesia spinal, posisi saat anestesia spinal, lokasi penusukan anestesia spinal, lama penyuntikan anestetik lokal, ketinggian blok anestesia spinal, jumlah perdarahan, penggunaan efedrin sebagai vasopresor, dan manipulasi operasi. ${ }^{2-4}$

Penekanan aortokaval akibat uterus yang membesardan penurunan resistensi pembuluh darah sistemik karena kehamilan diketahui sebagai penyebab penurunan tekanan darah sistemik pada wanita hamil. Penatalaksanaan yang dapat dilakukan untuk menurunkan dan juga mencegah hipotensi setelah anestesia spinal, yaitu menjaga posisi uterus miring ke kiri serta prehidrasi dengan kristaloid ataupun koloid. Hipotensi yang terjadi dapat diatasi dengan posisi trendelenberg, pemberian cairan melalui kateter intravena, terapi oksigen, dan pemberian obat-obat vasopresor. ${ }^{5,6}$ Pemberian dosis kecil anestetik lokal dengan penambahan opioid intratekal dapat meningkatkan potensi analgetika tanpa meningkatkan level blokade simpatis sehingga angka kejadian hipotensi dapat berkurang. ${ }^{2,7,8}$

Berdasarkan hasil penelitian tahun 2001 dinyatakan bahwa angka kejadian hipotensi selama anestesia spinal pada seksio sesaria mencapai 80\%, meskipun telah dilakukan prehidrasi cairan, posisi uterus miring ke kiri, dan penggunaan vasopresor. ${ }^{5,9}$
Penelitian tahun 2004 melaporkan bahwa angka kejadian hipotensi dengan pemberian prehidrasi cairan Ringer laktat sebanyak 15 $\mathrm{mL} / \mathrm{kgBB}$ sebelum anestesia spinal pada suatu grup kontrol yang menjalani seksio sesaria dengan teknik anestesi spinal adalah 43,33\%. ${ }^{10}$ Hasil penelitian tahun 2008 di Chulalongkorn, Thailand menunjukkan insidensi hipotensi pada pasien yang menjalani seksio sesarea dengan anestesia spinal sebesar 52,6\% dari 722 pasien. Masalah serius yang paling sering terjadi akibat anestesi spinal adalah hipotensi berat setelah onset obat tercapai. ${ }^{3}$

Tujuan penelitian ini adalah mengetahui insidensi hipotensi setelah tindakan anestesia spinal pada pasien yang menjalani operasi seksio sesarea dan faktor-faktor risiko yang memengaruhi hipotensi selama anestesi spinal di Rumah Sakit Dr. Hasan Sadikin (RSHS) Bandung.

\section{Subjek dan Metode}

Penelitian ini merupakan observasional potong lintang yang dilakukan setelah mendapatkan persetujuan dari Komite Etik Penelitian Kesehatan Fakultas Kedokteran Universitas Padjadjaran/Rumah Sakit Dr. Hasan Sadikin Bandung. Penelitian dilakukan pada bulan April-Mei 2015 dengan kriteria inklusi adalah wanita hamil yang akan dilakukan operasi seksio sesarea dengan teknik anestesi spinal di Instalasi Bedah Sentral Rumah Sakit Dr. Hasan Sadikin Bandung. Kriteria eksklusi adalah kontraindikasi dilakukan anestesia spinal dan kriteria pengeluaran adalah pasien yang gagal spinal. Penentuan besar sampel menggunakan batas waktu penelitian dalam periode AprilMei 2015 dan diperoleh jumlah sampel 90 orang.

Penelitian dilaksanakan dengan melakukan pencatatan data pasien yang dicatat dalam lembar penelitian oleh residen anestesia yang bertugas di Instalasi Bedah Sentral Rumah Sakit Dr. Hasan Sadikin Bandung dan tidak ada intervensi perlakuan dari peneliti terhadap pasien. Data yang dicatat adalah nama, usia, tinggi badan, dan berat badan. Variabel yang dicatat adalah diagnosis pasien, status fisik 
American's Society of Anesthesiology (ASA), tekanan darah, laju nadi, jumlah cairan prehidrasi (preloading), posisi pasien miring ke kiri dengan ganjal pinggul, dosis obat yang digunakan, dosis obat adjuvan, posisi pasien saat tindakan anestesia spinal, lokasi tusukan, lama penyuntikan obat spinal, dan ketinggian blokade anestesia spinal. Pengukuran tekanan darah sistol, diastol, laju nadi, serta saturasi oksigen dilakukan tiap 1 menit sampai 15 menit pertama, kemudian 2,5 menit sampai operasi selesai.

Penggunaan efedrin dicatat setiap terjadi hipotensi, yaitu penurunan tekanan darah sistol sebesar $20 \%$ dari tekanan darah sistol awal atau tekanan darah sistol kurang dari $90 \mathrm{mmHg}$ selama operasi. Jumlah cairan dan perdarahan selama operasi dicatat pula dalam lembar penelitian.

Analisis data univariabel dilakukan untuk melihat gambaran proporsi masing-masing variabel secara deskriptif. Data-data numerik disajikan dalam bentuk mean, nilai minimum, nilai maksimum, standar deviasi, range, serta median. Data diolah menggunakan program statistical product and service solutions (SPSS) versi 21.0 for windows.

\section{Hasil}

Selama bulan April-bulan Mei 2015 terdapat

\section{Tabel 1 Karakteristik Umum Subjek} Penelitian

\begin{tabular}{|c|c|}
\hline Variabel & n (\%) \\
\hline \multicolumn{2}{|l|}{ Usia } \\
\hline Mean \pm std deviasi & $30,93 \pm 6,46$ \\
\hline Range (min-maks) & $17,00-46,00$ \\
\hline \multicolumn{2}{|l|}{ BMI } \\
\hline Mean \pm std deviasi & $26,53 \pm 2,87$ \\
\hline Range (min-maks) & $21,09-36,73$ \\
\hline \multicolumn{2}{|l|}{ Status ASA } \\
\hline ASA 2 & $70(77,8 \%)$ \\
\hline ASA 3 & $20(22,2 \%)$ \\
\hline
\end{tabular}

Keterangan: $\mathrm{BMI}=$ body mass index; $\mathrm{ASA}=$ American Society of Anesthesiologists
90 wanita hamil yang dilakukan anestesia spinal untuk tindakan seksio sesarea di RSHS. Pasien dengan status fisik ASA II dan III dengan usia termuda adalah 17 tahun dan tertua 46 tahun (Tabel 1).

Dari penelitian ini didapatkan insidensi hipotensi pada wanita hamil yang dilakukan seksio sesarea dengan teknik anestesia spinal

Tabel 2 Insidensi Hipotensi Setelah Tindakan Anestesi Spinal

\begin{tabular}{ll}
\hline \multicolumn{1}{c}{ Kejadian Hipotensi } & Insidensi \\
\hline Ada & $44(49 \%)$ \\
Tidak ada & $46(51 \%)$ \\
\hline
\end{tabular}

sebanyak 44 dari 90 orang subjek penelitian (Tabel 2). Penggunaan obat vasopresor efedrin untuk mengatasi hipotensi pada penelitian ini dengan dosis rata-rata sebesar $10 \mathrm{mg}$ (Tabel 3).

Faktor risiko yang memengaruhi terjadinya hipotensi setelah dilakukan tindakan anestesia spinal pada wanita hamil yang dilakukan seksio

Tabel 3 Penggunaan Vasopresor Efedrin

\begin{tabular}{lc}
\hline \multicolumn{2}{c}{ Jumlah Efedrin (mg) } \\
\hline Mean \pm std deviasi & $10,00 \pm 6,12$ \\
Range (min-maks) & $5-20$ \\
\hline
\end{tabular}

sesarea adalah pemberian ganjal pinggul, jumlah pemberian cairan preloading, dosis bupivakain, dosis adjuvan fentanil, posisi saat tindakan anestesia spinal, lokasi penusukan anestesia spinal, lama penyuntikan anestetik spinal, ketinggian blokade, jumlah perdarahan selama pembedahan, dan jumlah efedrin yang digunakan (Tabel 4). Faktor-faktor risiko yang memengaruhi hipotensi setelah tindakan anestesi spinal menunjukkan hasil yang tidak bermakna secara statistika ( $p>0,05$; Tabel 5).

\section{Pembahasan}

Penelitian dilakukan pada 90 orang pasien 
Tabel 4 Karakteristik Faktor-faktor Risiko Hipotensi

\begin{tabular}{|c|c|}
\hline Variabel & n (\%) \\
\hline \multicolumn{2}{|l|}{ Ganjal pinggul } \\
\hline Ya & $55(61 \%)$ \\
\hline Tidak & $35(39 \%)$ \\
\hline \multicolumn{2}{|l|}{ Cairan preloading $(\mathrm{mL})$} \\
\hline Mean \pm std deviasi & $503,3 \pm 144,5$ \\
\hline Range (min-maks) & $200-1.000$ \\
\hline \multicolumn{2}{|l|}{ Dosis bupivakain (mg) } \\
\hline Mean士std deviasi & $12,4 \pm 0,5$ \\
\hline Range (min-maks) & $10-12,5$ \\
\hline \multicolumn{2}{|l|}{ Dosis adjuvan fentanil (mcg) } \\
\hline Mean \pm std deviasi & $25,0 \pm 0,0$ \\
\hline Range (min-maks) & $25-25$ \\
\hline \multicolumn{2}{|l|}{ Posisi saat anestesi spinal } \\
\hline Duduk & $90(100 \%)$ \\
\hline \multicolumn{2}{|l|}{ Lokasi tusukan } \\
\hline L 2-3 & $16(18 \%)$ \\
\hline L 3-4 & $69(77 \%)$ \\
\hline L 4-5 & $5(5 \%)$ \\
\hline \multicolumn{2}{|l|}{ Lama penyuntikan (detik) } \\
\hline Mean \pm std deviasi & $54,78 \pm 9,02$ \\
\hline Range (min-maks) & $30-60$ \\
\hline \multicolumn{2}{|l|}{ Tinggi blokade anestesi spinal } \\
\hline $\mathrm{T} 4$ & $15(17 \%)$ \\
\hline T5 & $2(2 \%)$ \\
\hline $\mathrm{T} 6$ & $55(61 \%)$ \\
\hline $\mathrm{T} 7$ & $5(6 \%)$ \\
\hline $\mathrm{T} 8$ & $13(14 \%)$ \\
\hline \multicolumn{2}{|l|}{ Jumlah perdarahan (mL) } \\
\hline Mean士std deviasi & $574,0 \pm 92,24$ \\
\hline Range (min-maks) & $450-950$ \\
\hline
\end{tabular}

wanita hamil yang menjalani operasi seksio sesarea menggunakan anestesi spinal dengan status fisik ASA kelas II dan III di Instalasi Bedah Sentral Rumah Sakit Dr. Hasan Sadikin Bandung selama bulan April-Mei 2015. Hasil penelitian didapatkan insidensi hipotensi setelah anestesi spinal, yaitu 44 orang (49\%). Definisi hipotensi pada penelitian ini adalah penurunan tekanan darah lebih dari $20 \%$ nilai normal atau penurunan tekanan darah sistol $<90 \mathrm{mmHg}$. Walaupun hipotensi didefinisikan sebagai tekanan darah arteri yang subnormal, sampai saat ini definisi yang pasti masih kontrovesial. $^{2}$

Efedrin merupakan vasopresor terpilih selama lebih dari 30 tahun untuk mengatasi hipotensi akibat anestesi spinal pada seksio sesarea bila upaya pencegahan hipotensi yang 
Tabel 5 Deskriptif Faktor-Faktor Risiko Hipotensi

\begin{tabular}{|c|c|c|c|}
\hline \multirow{2}{*}{ Variabel } & \multicolumn{2}{|c|}{ Hipotensi $n=90$} & \multirow{2}{*}{ Nilai p } \\
\hline & Ya $(n=44)$ & Tidak $(n=46)$ & \\
\hline Usia (tahun; mean $\pm \mathrm{SD}$ ) & $30,2 \pm 5,9$ & $31,7 \pm 7,0$ & 0,264 \\
\hline $\mathrm{TB}(\mathrm{cm} ;$ mean $\pm \mathrm{SD})$ & $157,7 \pm 5,0$ & $157,4 \pm 5,3$ & 0,890 \\
\hline $\mathrm{BB}(\mathrm{kg} ;$ mean $\pm \mathrm{SD})$ & $65,7 \pm 10,2$ & $66,2 \pm 7,4$ & 0,384 \\
\hline $\mathrm{BMI}($ mean $\pm \mathrm{SD})$ & $26,4 \pm 3,5$ & $26,7 \pm 2,2$ & 0,198 \\
\hline \multicolumn{4}{|l|}{ Ganjal pinggul } \\
\hline Ya & 25 & 31 & \multirow{2}{*}{0,301} \\
\hline Tidak & 19 & 15 & \\
\hline Cairan preloading $(\mathrm{mL} ;$ mean $\pm \mathrm{SD})$ & $511,4 \pm 136,3$ & $495,7 \pm 153,1$ & 0,244 \\
\hline Dosis bupivakain (mg; mean $\pm \mathrm{SD}$ ) & $12,4 \pm 0,4$ & $12,3 \pm 0,6$ & 0,331 \\
\hline Dosis fentanil (mcg; mean \pm SD) & $25,0 \pm 0,0$ & $25,0 \pm 0,0$ & 1,000 \\
\hline \multicolumn{4}{|l|}{ Lokasi penusukan } \\
\hline L2-3 & 9 & 7 & \\
\hline L3-4 & 33 & 36 & 0,765 \\
\hline L4-5 & 2 & 3 & \\
\hline Lama penyuntikan (detik; mean \pm SD) & $55,7 \pm 7,8$ & $53,9 \pm 10,1$ & 0,485 \\
\hline \multicolumn{4}{|l|}{ Ketinggian blokade spinal } \\
\hline $\mathrm{T} 4$ & 8 & 7 & \\
\hline $\mathrm{T} 5$ & 1 & 1 & \\
\hline T6 & 30 & 25 & 0,187 \\
\hline $\mathrm{T} 7$ & 0 & 5 & \\
\hline $\mathrm{T} 8$ & 5 & 8 & \\
\hline Perdarahan (mL; mean \pm SD) & $579,1 \pm 101,9$ & $569,1 \pm 82,2$ & 0,786 \\
\hline
\end{tabular}

Keterangan: $\mathrm{TB}=$ tinggi badan, $\mathrm{BB}=$ berat badan, $\mathrm{BMI}=$ Body mass index

konservatif gagal dilakukan. ${ }^{4,3}$ Pada penelitian ini digunakan efedrin rata-rata $10 \mathrm{mg}$ pada pasien yang mengalami hipotensi. Efedrin adalah obat golongan simpatomimetik yang berefek langsung terhadap reseptor alfa dan beta agonis dan efek tidak langsung terhadap presinaptik saraf dengan membantu pelepasan norepinefrin. Aliran darah uterus dikendalikan lebih besar oleh beta agonis dibanding dengan alfa agonis. ${ }^{5,10}$

Dari hasil penelitian, ketinggian blokade anestesi maksimal tercapai $\geq \mathrm{T}_{4}$ sebanyak $17 \%$ yang berkaitan dengan meningkatnya risiko hipotensi. Efek ketinggian blokade sensorik diyakini sebagai akibat dari blokade terhadap sistem saraf simpatis. Ketinggian blokade saraf simpatiskurangdari $\mathrm{T}_{4}$ akan terjadikompensasi vasokonstriksi pembuluh darah di ekstremitas atas sehingga mengurangi penurunan tekanan darah. Pada level blokade anestesi spinal yang lebih tinggi, mekanisme kompensasi ini akan ikut terblokade bersamaan dengan serabut saraf akselerator kardiak. Ketinggian level blokade anestesia spinal berhubungan secara relatif dengan penurunan tekanan darah sistol yang lebih besar. Walaupun demikian, hanya terdapat variasi kecil dari ketinggian blokade yang terjadi pada pasien hamil yang menjadi subjek penelitian ini. ${ }^{3,9}$

Penelitian terhadap faktor risiko hipotensi 
pada wanita hamil yang dilakukan seksio sesarea dengan anestesia spinal diidentifikasi dengan menggunakan analisis univariabel yang menunjukkan hasil tidak bermakna $(p>0,05)$. Hal ini berbeda dengan penelitian sebelumnya yang telah menunjukkan faktor-faktor risiko yang memiliki kaitan erat dengan insidensi hipotensi pada wanita hamil yang dilakukan anestesi spinal, yaitu usia, tinggi badan, berat badan, BMI, perubahan posisi uterus miring ke kiri dengan ganjal pinggul, penggunaan cairan prehidrasi, dosis obat anestetik lokal bupivakain, penggunaan fentanil intratekal sebagai adjuvan obat anestetik lokal, posisi saat anestesi spinal, lokasi penusukan anestesi spinal, lama penyuntikan obat anestesia spinal, ketinggian blokade anestesia yang dicapai, jumlah perdarahan selama operasi $>500 \mathrm{~mL}$, dan jumlah efedrin yang digunakan untuk mengatasi hipotensi. ${ }^{5-9}$

Usia merupakan salah satu faktor risiko hipotensi pada pemberian anestesia spinal yang sama namun penurunan tekanan darah pasien yang berusia lebih muda akan lebih ringan daripada yang lebih tua. Hal tersebut mungkin disebabkan lebih tingginya tonus autonom pembuluh darah yang tersisa setelah denervasi simpatis dan juga karena refleks kompensasi yang lebih aktif. Penurunan curah jantung akan sesuai dengan bertambahnya usia. Hal tersebut juga menjelaskan penurunan tekanan darah secara proporsional yang lebih besar pada pasien lanjut usia setelah terjadi vasodilatasi perifer. Angka kejadian hipotensi meningkat secara progresif setelah usia 50 tahun., ${ }^{4,6}$

Dari hasil suatu penelitian dikatakan bahwa berat dan tinggi badan merupakan variabel yang signifikan untuk memprediksi ketinggian maksimal blokade anestesia spinal. Tinggi badan dan berat badan memberikan pengaruh terhadap penyebaran blokade anestesia yang luas sehingga dosis bupivakain yang digunakan harus disesuaikan. Penelitian yang dilakukan pada tahun 2004 menyatakan bahwa dosis bupivakain hiperbarik yang disesuaikan dengan tinggi badan dan berat badan pasien jika digunakan kombinasi dengan diamorfin 0,4 mg akan memberikan level anestesia yang optimal pada pasien yang menjalani seksio sesarea. ${ }^{9}$

Obesitas dalam kehamilan berpengaruh besar pada perubahan fisiologi ibu hamil. Pada posisi telentang terjadi risiko kardiovaskular terhadap perubahan volume dan kapasitas paru, perubahan rasio ventilasi dan perfusi, dan meningkatkan tekanan pada pembuluh aorta dan vena kava yang akan memperberat terjadinya hipotensi. Terjadinya pembesaran atau pelebaran vena pada ruang epidural menyebabkan penekanan rongga subaraknoid dan mengurangi cairan serebrospinalis. ${ }^{2,6,8}$

Penekanan aorta kaval dikurangi dengan perubahan posisi uterus dengan memiringkan pasien ke kiri, tindakan ini tidak sepenuhnya menurunkan kejadian hipotensi. Kemiringan abdomen yang tepat untuk dapat mengurangi tekanan aortokaval masih belum diketahui. Penelitian tahun 1976 pada wanita hamil yang dilakukan perubahan posisi uterus miring ke kiri dengan pemberian cairan intravaskular, memperlihatkan kombinasi cairan dan posisi uterus miring ke kiri tidak mencegah hipotensi. Penelitian selanjutnya mungkin diperlukan untuk meneliti pencegahan hipotensi dengan memposisikan uterus miring ke kiri. ${ }^{3,8}$

Pemberian cairan prehidrasi (preloading) sebelum dilakukan tindakan anestesia spinal pada penelitian ini dalam rentang 200-1.000 $\mathrm{mL}$ dengan pemberian preloading rata-rata sekitar $500 \mathrm{~mL}$. Hasil penelitian tahun 1960an, menyatakan bahwa pemberian preloading cairan kristaloid secara cepat dalam jumlah 500-1.000 mL (10-20 mL/kgBB) adalah metode yang aman dan efektif untuk mencegah hipotensi. Preloading cairan kristaloid (10-20 $\mathrm{mL} / \mathrm{kgBB}$ ) telah diberikan secara luas untuk mencegah hipotensi setelah tindakan anestesi regional. Beberapa penelitian menunjukkan insidensi hipotensi menurun secara signifikan dari $71 \%$ pada pasien yang tidak diberikan preloading menjadi $55 \%$ pada pasien yang diberikan preloading. ${ }^{3,5}$

Dosis bupivakain yang dipergunakan pada penelitian ini berkisar pada rentang 10-12,5 mg. Dari 90 orang subjek penelitian didapatkan dosis bupivakain $12,5 \mathrm{mg}$ sebanyak 96\% dan dosis bupivakain $10 \mathrm{mg}$ sebanyak 
4\% karena tinggi badan pasien $<150 \mathrm{~cm}$. Risiko hipotensi, mual, dan muntah pada dosis rendah anestetik lokal pada seksio sesarea yang dikombinasikan dengan opioid akan mengurangi insidensi hipotensi, tetapi hal ini tidak akan menghilangkan kejadian hipotensi setelah tindakan anestesi. Beberapa penelitian menyatakan bahwa pengurangan dosis obat anestetik lokal $<7,5 \mathrm{mg}$ untuk anestesi spinal akan mengurangi angka insiden serta derajat hipotensi. Pemberian dosis rendah anestetik lokal yang dikombinasikan dengan opioid pada seksio sesarea dapat mengurangi insidensi hipotensi. ${ }^{7-9}$

Pada penelitian ini didapatkan hasil dari 90 orang subjek penelitian, $100 \%$ pasien dilakukan dalam posisi duduk. Penyuntikan larutan anestetik lokal hiperbarik pada pasien dengan posisi duduk akan menghasilkan blokade yang terbatas. Walaupun demikian, blokade yang terbatas ini akan meluas seperti blokade yang terjadi pada pasien yang diposisikan telentang segera setelah penyuntikan obat anestesia spinal. Pemberian dosis kecil anestetik lokal membatasi penyebaran obat hanya di sekitar sakrum dan daerah lumbal bawah pada saat pasien ditidurkan. Jika pemberian volume anestetik lokal yang dipergunakan lebih besar maka tetap akan terjadi penyebaran obat ke daerah lumbal atas dan daerah torakal.

Mempertahankan pasien tetap duduk setelah penyuntikan obat anestesia lokal akan menghasilkan blokade anestesia yang adekuat, tetapi memiliki dua kekurangan. Kekurangan pertama adalah penyebaran blok anestesi yang lebih lama setelah penyuntikan anestetik lokal hiperbarik sehingga pasien akan diposisikan tidur telentang untuk menunggu penyebaran blokade anestesi. Kekurangan kedua adalah risiko hipotensi yang lebih berat akibat pooling pembuluh darah vena di ekstremitas bawah sehingga pada saat blokade anestesia tercapai akan memblok persarafan simpatis. ${ }^{10}$

Lama penyuntikan anestetik lokal adalah salah satu faktor risiko terjadi hipotensi. Pada penelitian ini dari 90 orang subjek penelitian didapatkan waktu penyuntikan adalah 30-60 detik. Waktu penyuntikan terbanyak dilakukan selama 60 detik. Efek kecepatan penyuntikan anestetik lokal terhadap penyebaran anestetik lokal masih kontroversial sampai saat ini.

Hasil penelitian sebelumnya menunjukkan penyebaran obat spinal yang lebih tinggi bila dilakukan penyuntikan yang cepat, namun pada penelitian lain menunjukkan penyebaran yang lebih tinggi pada penyuntikan yang lambat dan ada penelitian yang tidak menunjukkan perbedaan keduanya. Pada penelitian terakhir memperlihatkan bahwa penyuntikan lambat bupivakain hiperbarik $10 \mathrm{mg}$ selama 60 detik dan 120 detik dapat mengurangi insidensi serta efek samping hipotensi selama anestesi spinal pada operasi seksio sesarea. ${ }^{11}$

Jumlah perdarahan operasi yang terjadi tidaklah berbeda signifikan antara kelompok hipotensi dan kelompok tidak hipotensi, dengan rata-rata $547 \mathrm{~mL}$. Perkiraan jumlah perdarahan yang dicatat oleh residen anestesi yang bertugas tidakakurat karena berdasarkan jumlah kassa, lapangan operasi, dan tabung suction. Anestesia spinal dapat menyebabkan depresi kardiovaskular yang lebih berat pada kondisi hipovolemia sehingga memperberat hipotensi yang terjadi. Pengelolaan hipotensi akibat kehilangan darah dilakukan dengan terapi cairan dan transfusi. 8,12

Faktor risiko di atas menurut teori dan hasil penelitian sebelumnya merupakan faktor risiko kejadian hipotensi setelah tindakan anestesia spinal, namun tidak menunjukkan hubungan bermakna $(p>0,05)$. Kemungkinan perbedaan insidensi pada hasil penelitian ini dengan beberapa penelitian sebelumnya adalah perbedaan jumlah sampel penelitian. Jumlah sampel pada penelitian sebelumnya >300 dan menunjukkan hasil yang bermakna antara insidensi hipotensi dan faktor-faktor risiko hipotensi.

\section{Simpulan}

Insidensi hipotensi pada pasien yang menjalani seksio sesarea dengan teknik anestesia spinal di Rumah Sakit Dr. Hasan Sadikin Bandung sebanyak $49 \%$ dengan faktor risiko yang diduga menyebabkan hipotensi maternal tidak menunjukkan hubungan antara hipotensi dan 
faktor risiko. Dibutuhkan penelitian lanjutan dengan jumlah sampel yang lebih besar dan waktu yang lebih lama sehingga dapat dilihat hubungan antara insidensi hipotensi dan faktor-faktor risiko hipotensi.

\section{Daftar Pustaka}

1. Baraka A, MD, FRCA. Editorial: can we minimize hypotension following spinal anesthesia for cesarian section. MEJ Anesth. 2010;5:20.

2. Somboonviboon W, Kyokong O, Narasethakamol A. Incidence and risk factors of hypotension and bradycardia after spinal anesthesia for cesarian section. J Med Assoc Thai. 2008;91(2):181-7.

3. Salman $\mathrm{OH}$, Yehia AH. Randomized double-blind comparison of intravenous ephedrine and hydroxyethyl starch 6\% for spinal-induced hypotension in elective cesarean section. Ain-Shams Anesthesiol. 2014;07:221-5.

4. Chumpathong $S$, Chinachoti T, Visalyaputra $\mathrm{S}$, Himmunngan $\mathrm{T}$. Incidence and risk factors of hypotension during spinal anesthesia for cesarean section at Siriraj Hospital. J Med Assoc Thai. 2006;89(8):1127-32.

5. Sungsik P. Prediction of hypotension in spinal anesthesia. Korean J Anesthesiol.
2013;65(4):291-2.

6. Jadon A. Complication of regional and general anaesthesia in obstetric practice. Indian J Anaesth. 2010;54;5:415-20.

7. Mitra JK, Roy J, Bhattacharyya P, Yunus M, Lyngdoh NM. Changing trends in the management of hypotension following spinal anesthesia in cesarean section. J Postgrad Med. 2013;59:121-6.

8. Harten JM, Boyne I, Hannah P, Varveris D, Brown A. Effects of a height and weight adjusted dose of local anaesthetic for spinal anaesthesia for elective caesarean section. Anaesthesia. 2005;60:348-53.

9. Rodrigues FR, Brandao MJN. Regional anesthesia for cesarean section in obese pregnant woman: a retrospective study. Rev Bras Anestesiol. 2011;61(1):13-20.

10. Ngan Kee WD. Prevention of maternal hypotension after regional anaesthesia for caesarean section. Curr Opin Anaesthesiol. 2010;23:304-9.

11. Singh SI, Morley-Forster PK, Shamsah M. Influence of injection rate of hyperbaric bupivacaine on spinal block in parturients: a randomized trial. Can J Anesth. 2007;54(4):290-5.

12. Javed S, Hamid S, Amin F, Mahmood KT. Spinal anesthesia induced compilcations in caesarean section-a review. J Pharm Sci Res. 2011;3(10):1530-8. 